\title{
PROJETO SAÚDE DO IDOSO INSTITUCIONALIZADO ATUAÇÃO DOS PROFISSIONAIS NA ATENÇÃO À SAÚDE DE IDOSOS RESIDENTES EM INSTITUIÇÃO DE LONGA PERMANÊNCIA
}

\author{
Márcia Denise Moreira ROCHA ${ }^{1}$ \\ Maria Celina da Piedade RIBEIRO
}

\begin{abstract}
RESUMO: Sabemos que todo ser humano necessita de conviver com outras pessoas, participar da sociedade. Mas nem sempre é o que acontece com idosos que residem em Instituição de longa Permanência para Idosos (ILPI). Muitas vezes estes idosos são cercados por suas próprias emoções e limitações, se prendem em seus pensamentos de isolamento, saudades, rejeição, medo, fragilidade, sentimentos que os impedem de aproveitar a vida e apreciá-la como algo precioso. Sentem-se menores e menos importantes por não haver sentido e felicidade capazes de permitir-lhes enxergar a vida com outros olhos. Não poder contar com parentes e amigos em todos os momentos e principalmente diante da enfermidade física e psíquica, é um dos fatores que levam ao vazio, a depressão e ao medo da morte. Diante da realidade dos 52 idosos ( 30 mulheres e 22 homens) residentes em Três Corações - MG, surgiu a necessidade de promover o envelhecimento saudável, melhorando a qualidade de vida, bem como a auto-estima, através de convívio social e a participação em atividades direcionadas ao trabalho e ao lazer da instituição, por meio de profissionais capazes de identificar fatores de proteção, manutenção e recuperação da saúde dos idosos da ILP.
\end{abstract}

PALAVRAS-CHAVE: Instituição. Idosos. Isolamento. Envelhecimento saudável. Profissionais.

\begin{abstract}
We know that every human being needs to live with other people, joining to society. But not always it happens with elderly that live in Long Stay Institution (LSI). Many times these elderly are surrounded by their selves emotions and limitations, get stuck to their selves thoughts of isolation, miss, rejection, fear, fragility, feelings that prevent them from making the most of life and enjoying it like something precious. They feel inferior and less important because they don't have sense and happiness that make them see the life with other eyes. One of the factors that induce to emptiness, depression and fear of the death it's can not count on relatives and friends in all moments, principally during the physic and psychic disease. In face of the reality lived by 52 elderly (30 women and 22 men) resident in Três Corações - MG, it's arisen the need to promote the healthy aging, improving the quality of life and selfesteem through social contact and participation in activities directed to the work and leisure in the institution, by means of professional able to identify protecting, maintenance and recovery factors for health of elderly that live in LSI.
\end{abstract}

KEYWORDS: Institution. Elderly.Isolation. Healthy aging.Professional.

\footnotetext{
${ }^{1}$ Graduada em Nutrição pela Universidade Vale do Rio Verde (UninCor).

E-mail: marcianutricionista@hotmail.com

${ }^{2}$ Enfermeira, Mestre, docente do Curso de Enfermagem da Universidade Vale do Rio Verde (UninCor).

E-mail: maria.ribeiro@unincor.edu.br
} 


\section{INTRODUÇÃO}

Este tema foi escolhido frente às reais necessidades que os idosos institucionalizados apresentam. $\mathrm{O}$ idoso institucionalizado carece de atenção e acompanhamento por profissionais da saúde, estudantes dos cursos de nutrição, odontologia, enfermagem, fisioterapia, psicologia, educação física, serviço social, agronomia, pessoas capazes de oferecerem assistência à sua saúde, seja física ou emocional.

Por se tratar de um grupo de pessoas idosas, sabemos que há possibilidade de as necessidades serem semelhantes de um indivíduo para o outro, ou diferentes em relação aos grupos feminino e masculino. Por outro lado, a existência de uma mesma enfermidade física em vários idosos pode apresentar estágios diferentes de um para outro, chegando ao estágio mais avançado em alguns. $\mathrm{O}$ mesmo pode ocorrer quanto à saúde emocional.

Os idosos institucionalizados refletem suas carências por meio de alterações, como tristeza, depressão, sensação de abandono, regressão, falta de apetite, desmotivação para a vida, entre outros. O objetivo deste projeto é promover saúde e bem-estar, para que os idosos se sintam estimulados a viver com prazer. O desafio dos profissionais da saúde é promover qualidade de vida e de morte.

\section{REFERENCIAL TEÓRICO}

A população idosa no mundo tem mostrado um crescente aumento, com estimativas que indicam uma elevação desses índices para as próximas décadas. Em contraposição, percebe-se que nossa sociedade confunde a imagem do envelhecer e da velhice com uma fase da vida em declínio, tanto no aspecto físico e psíquico como nas relações sociais (GUIDETTI \& PEREIRA， 2008, p.120).

O indivíduo idoso é aquele que vive a última etapa do ciclo vital (HERÉDIA, 2004, p. 21). Para FRANÇA (citado por SOARES et al., 2009, p. 136), a velhice é um processo pessoal, natural, indiscutível e inevitável para qualquer ser humano na evolução da vida.

A velhice é permeada pelas questões de gênero (SAFFIOTTI, 2005; ALVES, 2002, citados por PAVAN et al., 2008). As mulheres idosas experimentam uma probabilidade maior 
de ficarem viúvas, em situação sócioeconômica desvantajosa e com necessidades especiais (GOLDANI, 2009). Nos últimos anos, tem ocorrido um acentuado aumento nas taxas de institucionalização de idosos, como consequência da maior participação feminina na força de trabalho. No Brasil, existem 200 mil abrigos para idosos, e a maior parte de asilados é do sexo feminino (CHAMOVICZ \& GRECO, 1999; MONTENEGRO \& SILVA, 2007 citados por PAVAN et al., 2008).

O idoso institucionalizado constitui, quase sempre, um grupo privado de seus projetos, pois se encontra afastado da família, da casa, dos amigos, das relações nas quais sua história de vida foi construída. Pode-se associar a essa exclusão social as marcas e sequelas das doenças crônicas não transmissíveis, que são os motivos principais de sua internação, inclusive nas Instituições de Longa Permanência (ILP) (JÚNIOR E TAVARES, 2004/2005, p.148).

A transferência do próprio lar para uma instituição de longa permanência (ILP) é sempre um grande desafio para os idosos, pois se deparam com uma transformação muitas vezes radical do seu estilo de vida, sendo desviados de todo seu projeto existencial. Segundo BORN (1996), muitos idosos encaram o processo de institucionalização como perda de liberdade, abandono pelos filhos, aproximação da morte, além da ansiedade quanto à condução do tratamento pelos funcionários. Contudo, não devemos esquecer que, muitas vezes, essa ILP cumpre papel de abrigo para o idoso excluído da sociedade e da família, abandonado e sem um lar fixo, podendo se tornar o único ponto de referência para uma vida e um envelhecimento dignos (JÚNIOR E TAVARES, 2004/2005, p.152).

O mundo de uma instituição de longa permanência (ILP) é o ambiente de geração de significados constituído por um cenário rico em simbolismos de rotinas, costumes, crenças e rituais. Para compreendê-los, faz-se necessário ouvir, observar e interpretar. Isto quer dizer estudar as cenas culturais para descobrirmos as diferentes visões culturais da situação social que, muitas vezes, penetram de modo imperceptível nas atividades cotidianas dos profissionais que trabalham com idosos (LENARDT et al., 2006, p.118).

A capacitação de profisssionais para atuar na área de envelhecimento e saúde do idoso é uma das ações 
prioritárias da política nacional do idoso no Brasil, em função do acelerado envelhecimento populacional do país (MOTTA et al., 2008).

\subsection{SAÚDE E ENVELHECIMENTO}

Embora o envelhecimento populacional mude o perfil de adoecimento dos brasileiros, obrigandonos a dar maior ênfase na prevenção e tratamento de doenças crônicas não transmissíveis, nossa maior atenção precisa se voltar para as políticas que promovam a saúde, que contribuam para a manutenção da autonomia e valorizem as redes de suporte social (LENARDT et al., 2006, p.118).

\section{BUSSE \& BLAZER} conceituam o termo envelhecer como as alterações físicas que se desenvolvem na idade adulta, resultando em um declínio na eficiência do funcionamento (citado por VIVAN \& ARGIMON, 2009). O sentimento de controle e a ausência de sequelas ou incapacidades associadas pode ser $\mathrm{o}$ que contribui para os idosos expressarem satisfação em relação à vida. Porém, quando eles se deparam com a falta de autonomia e a necessidade de assistência, ou dependência nas atividades da vida diária, a qualidade de vida parece estar em risco (RAMOS et al., 2003 citado por VIVAN \& ARGIMON, 2009).

A capacidade funcional vem sendo vista como um novo paradigma de saúde para o idoso. A presença de uma doença, a falta de autonomia, fatores culturais, socioeconômicos e estilo de vida podem comprometer a capacidade funcional de um indivíduo, afetando o bem-estar e o processo de envelhecimento saudável (RAMOS, 2003; FIEDLER \& PERES, 2008; GUEDEA et al., 2008, citados por VIVAN E ARGIMON, 2009).

As condições de saúde da população idosa podem ser determinadas a partir de seus perfis de morbidade e mortalidade, da presença de déficits físicos e cognitivos, da utilização de serviços de saúde, além de outros indicadores mais específicos, como a percepção da própria saúde (LIMA et al., 2003, citado por LENARDT et al., 2009, p.228).

Para as instituições que abrigam idosos, é imprescindível que tenham disponíveis os registros atualizados sobre as condições de saúde, bem como sobre os graus de dependência funcional e as deficiências físicas e cognitivas. Esses registros contribuem para $\mathrm{o}$ 
monitoramento de alterações sobre o estado inicial, avaliação da eficácia terapêutica, identificação de potencialidades, riscos e demandas de cuidados, e guiam o planejamento da assistência gerontológica multiprofissional (LENARDT et al., 2009, p.228).

De acordo com a Organização Mundial de Saúde (OMS, 2005, citado por LENARDT et al., 2009, p.228), quando os fatores de risco comportamentais e ambientais de doenças crônicas e de declínio funcional são mantidos baixos, as pessoas permanecem sadias e capazes de cuidar de sua própria vida à medida que envelhecem. A saúde, participação e segurança constituem-se nos três pilares da estrutura política para $\mathrm{o}$ envelhecimento ativo. Espera-se que o aumento na duração da vida seja acompanhado por uma compressão da morbidade em todas as faixas etárias, o que se traduziria em uma vida mais longa e de melhor qualidade para um maior número de idosos (LENARDT et al., 2009, p.228).

\subsection{IMPORTÂNCIA DA ATUAÇÃO DOS PROFISSIONAIS DA SAÚDE}

\subsubsection{Nutrição}

A nutrição, a saúde e o envelhecimento estão relacionados entre si, por isso o envelhecimento saudável está relacionado à manutenção de um estado nutricional adequado e à alimentação equilibrada (AMADO et al., 2007, p.366).

A alimentação balanceada e equilibrada propicia um aumento na qualidade de vida dos seres humanos. Assim sendo, para a manutenção de um bom estado nutricional, torna-se necessário ingerir, diariamente, uma quantidade ideal de energia e nutrientes para suprir as necessidades energéticas (OLIVEIRA, 2008).

O alimento é o combustível para o corpo exercer suas capacidades funcionais. É composto por nutrientes que indicam sua composição química. Estes são: proteínas, carboidratos (açúcares), lipídios (gordura), vitaminas, sais minerais, fibras e água (MONTOVANI, p.167).

O envelhecimento saudável exige a adoção de um estilo de vida que inclua alimentação equilibrada acompanhada de atividade física $\mathrm{e}$ 
mental e, ainda, convívio social (BANDEIRA et al., 2006, p.29).

A alimentação é uma atividade básica para a sobrevivência, sendo influenciada por inúmeros fatores: aspectos socioculturais, idade, estado físico e mental, situação econômica e estado geral de saúde. As alterações morfofisiológicas, funcionais, comportamentais e psicossociais, podem comprometer o estado nutricional do idoso, interferindo desde a aquisição e preparo dos alimentos, como também a utilização dos nutrientes pelo organismo (SOUZA, 2009, citado por SILVA, p128). O cuidado nutricional ultrapassa as orientações restritamente relacionadas à alimentação, devendo dar-se muita atenção ao ambiente em que o idoso está inserido. (BANDEIRA et al., 2006, p.33).

\subsubsection{Odontologia}

Segundo HOLM-PEDERSEN \& LÖE (1996), odontologia geriátrica é o termo frequentemente aceito para a disciplina da Odontologia que cuida da saúde bucal da população idosa, em especial dos pacientes que se apresentam debilitados (citado por SHINKAI \& CURY, 2000, p.1102).
O idoso institucionalizado, seja incapaz ou não, requer cuidado e atenção seja por enfermeiros, cuidadores ou, ainda, por outras pessoas que estejam ligadas a eles. Toda equipe deve estar ciente dos potenciais problemas odontológicos no idoso e da importância da higiene bucal diária, principalmente à medida que as condições debilitantes sistêmicas se agravam (IACOPINO, 1997; REYNOLDS, 1997, citado por SHINKAI \& CURY, 2000, p.1102).

A mastigação é indispensável para uma boa nutrição do idoso, porquanto o processo de digestão tem seu início na cavidade oral. Com o envelhecimento, os hábitos de mastigação se modificam acentuadamente devido ao aparecimento frequente de cáries $\mathrm{e}$ doenças periodontais, à ausência de dentes e às próteses inadaptadas total ou parcialmente ou em estado precário de conservação. Em razão disso, o consumo de carnes, frutas e vegetais frescos se torna mais difícil e os idosos tendem a consumir alimentos mais macios, pobres em fibras, vitaminas e minerais (CAMPOS et al., 2000, p.160).

A manutenção precária da saúde bucal nesses pacientes pode levar a graves complicações de ordem local 
(cáries extensas, periodontopatias progressivas, lesões de mucosas e infecções oportunistas) e de ordem sistêmica (SLAVKIN, 1999 citado por SHINKAI \& CURY, 2000, p.1105). Devido a esses fatores, torna-se necessária a avaliação odontológica constante de idosos residentes em instituições.

A saúde bucal é parte integrante e inseparável da saúde geral do indivíduo e está relacionada diretamente com as condições de saneamento, alimentação, moradia, trabalho, educação, renda, transporte, lazer, liberdade, acesso e posse da terra, aos serviços de saúde e a informação (CFO, 1993, citado por SHINKAI \& CURY, 2000, P.1101).

\subsubsection{Enfermagem}

O enfermeiro é um dos profissionais inseridos no contexto da multidisciplinaridade das Instituições de Longa Permanência e, portanto, necessita estar presente nelas. De acordo com a Lei 7498/86, apresenta-se como atividade privativa do enfermeiro: o planejamento, organização, coordenação, execução e avaliação do serviço de enfermagem, ou seja, onde houver profissional de enfermagem de nível médio (técnicos e auxiliares em enfermagem) e outros profissionais que realizam o cuidado, há necessidade de um enfermeiro para liderar e direcionar o trabalho desses profissionais (RIBEIRO et al., 1996, citado por ANDRADE et al., 2005, p.65). Todavia, essa realidade ainda não se faz presente na maioria das Instituições de Longa Permanência (ANDRADE et al., 2005, p.65).

De acordo com SANTOS et al., (2009), o enfermeiro que atuar na área gerontogeriátrica deve considerar alguns pontos importantes, como:

- permitir ao idoso melhorar ou manter o bem-estar e viver de maneira autônoma no seu domicílio;

- participar da análise dos cuidados de saúde para o idoso e ajude a elaborar estratégias adaptáveis a esse ser humano;

- centralizar os cuidados não somente nas doenças, mas no idoso e em suas necessidades;

- desenvolver modelos de cuidados que atendam o idoso e a sua família; trabalhar em uma abordagem multidisciplinar e interdisciplinar, procurando partilhar as responsabilidades;

- promover os cuidados domiciliares, incluindo aí os cuidadores; 
- tornar-se defensor dos direitos dos idosos;

- ampliar cada vez mais os seus conhecimentos, não só em gerontogeriatria, mas em diferentes domínios disciplinares;

A enfermagem gerontogeriátrica é uma especificidade da enfermagem que cuida do idoso em todos os níveis de prevenção, desde a promoção da saúde até a reabilitação (SANTOS, 2006).

\subsubsection{Psicologia}

O interesse da psicologia sobre a velhice é relativamente recente, visto que a expansão sistemática da Gerontologia só ocorre no final da década de 1950, principalmente em função do rápido crescimento no número de pessoas idosas (ARAUJO \& CARVALHO, 2004/2005, p.5).

Dentre os diversos transtornos que afetam os idosos, a saúde mental merece especial atenção. Depressão e demência têm incapacitado idosos em todo o mundo por levarem à perda da independência e, quase inevitavelmente, da autonomia (GORDILHO et al., 2000 citado por BENEDETTI et al., 2008). As desordens mentais comprometem $20 \%$ da população idosa, entre as quais se destacam a demência e a depressão como prevalentes (ABBOTT et al., 2004, citado por BENEDETTI et al., 2008). No Brasil, aproximadamente 10 milhões de idosos sofrem de depressão (SNOWDON, 2002, citado por BENEDETTI et al., 2008).

A depressão pode ser definida como um transtorno de humor, que é um distúrbio psicológico que se expressa através de uma ampla variedade de transtornos físicos e funcionais (BALLONE, 2008, citado por ANDRADE et al., 2005, p.58).

É o transtorno de humor mais frequente entre os idosos, levando à perda da autonomia e agravamento de quadros patológicos preexistentes. Está associada a maior risco de morbidade e mortalidade, aumento da utilização de serviço de saúde, negligência no auto cuidado, atenção reduzida aos regimes terapêuticos e maior risco de suicídio (GALHARDO, 2009, citado por SILVA, p.183).

A depressão relativa ao envelhecimento é provocada, em primeiro lugar, por situações que questionam valores existenciais importantes como doenças que colocam a vida em perigo, morte ou doença grave de ente próximo, aposentadoria, 
mudança de habitat, pesadas perdas materiais, acontecimentos e conflitos dramáticos que comprometem a esfera afetiva e o fato de que a maior parte de suas fraquezas toma um caráter irreversível (GALHARDO, 2009, citado por SILVA, p.183).

Idosos deprimidos apresentam taxa mais elevada de mortalidade do que seria esperado, mostrando que a depressão acrescenta um risco mesmo quando os problemas físicos estão sob controle (GALHARDO, 2009, citado por SILVA, p.184).

Devido à falta de conscientização da população com seus "velhos", os idosos de ILPI, principalmente os vindos de famílias pobres e que precisam de ajuda do Estado, não recebem $\mathrm{o}$ atendimento psicológico de que necessitam para amenizar o sofrimento diante da solidão e do sentimento de tristeza (CARDOSO, 2006).

De acordo com CARDOSO (2006), o ser humano não deve viver muito tempo no vazio, senão acaba por estagnar-se; suas potencialidades transformam-se em morbidez e desespero e, eventualmente, em atividades destrutivas.

\subsubsection{Fisioterapia}

Como a velhice é um período da vida com alta prevalência de limitações físicas, perdas cognitivas, declínio sensorial, sintomas depressivos e isolamento social, a fisioterapia assume um papel importante não somente na reabilitação como também na melhora da qualidade de vida dos idosos (CARVALHO et al., 2007, p.125).

Deve-se ressaltar que as principais alterações biológicas causadas pelo passar dos anos são a diminuição da massa muscular e da densidade mineral óssea, a perda da força muscular, a deficiência da agilidade, da coordenação motora, do equilíbrio, da mobilidade articular e de várias funções orgânicas corporais, além da maior rigidez das cartilagens, dos tendões e dos ligamentos, maior trabalho ventilatório aos esforços, queda do tempo de reação e da condução nervosa e menor número e tamanho dos neurônios (DELIBERATO, 2002, citado por CARVALHO et al., 2007, p.126). No entanto, é preciso levar em consideração que a atuação do fisioterapeuta com a terceira idade confronta com uma série de desafios. 


\subsubsection{Educação Física}

A prática de atividade física atua como forma de prevenção e reabilitação da saúde do idoso, fortalecendo os elementos da aptidão física (resistência, equilíbrio, flexibilidade e força), sendo que se acredita que essa melhora está associada diretamente à independência e à autonomia do idoso, mantendo por mais tempo a execução das atividades diárias da vida, tanto as físicas quanto as instrumentais (GOBBI, 1997; LEE et al., 1995; SHEPHARD, 1991; SKELTON et al., 1995, citados por MELO et al., 2003).

Para a OMS, a participação em atividades físicas leves e moderadas pode retardar os declínios funcionais. Assim, uma vida ativa melhora a saúde mental e contribui na gerência de desordens como a depressão e a demência. Existe evidência de que idosos fisicamente ativos apresentam menor prevalência de doenças mentais do que os não-ativos (CRIAG, 2003, p.303, citado por BENEDETTI et al., 2008).

Segundo BENEDETTI et al. (citado por MELO et al., 2003), as ILPIs não realizam atividades ocupacionais durante o dia e, ainda, devido ao declínio do organismo, os idosos dão preferência às atividades menos exigentes e que requeiram menor esforço, acontecendo, com isso, um fenômeno interessante que termina convertendo-se em um ciclo vicioso: à medida que há o incremento da idade, o indivíduo tende a se tornar menos ativo, por conseguinte, suas capacidades físicas diminuem, começa a aparecer o sentimento de velhice, que pode, por sua vez, causar estresse, depressão e levar a uma redução da atividade física e, consequentemente, à aparição de doenças crônico-degenerativas, que por si só contribuem para o envelhecimento. Mais que a doença crônica, é o desuso das funções fisiológicas que pode gerar mais problemas. A maioria dos efeitos do envelhecimento ocorre por imobilidade e má adaptação e não por doença crônica (MATSUDO, 1997, citado por MELO et al., 2003).

Alguns benefícios da atividade física para o idoso:

(MARCONCIN et al., Revista Transdisciplinar de Gerontologia, 2010, p. 21-22)

1. Benefícios físicos: relacionados com as melhoras físicas: mais agilidade, 
mobilidade, força, equilíbrio, entre outras;

2. Benefícios para a vida: relacionados

à melhora na realização de outras atividades, ou em outros setores, como a família;

3. Benefícios emocionais: sensação de liberdade, extravasamento e paz espiritual.

\subsubsection{Agronomia}

Devido à necessidade da realização de atividades pelos idosos capazes de as realizarem, e também para que tenham contato direto com a terra e prazer de se sentirem úteis a si mesmos e às pessoas de seu convívio, torna-se necessária a prática de cuidados com a horta presente na ILPI, sendo que, dessa forma, contribuem para a saúde tanto emocional quanto física, melhorando a autoestima e consumindo alimentos frescos, fontes de vitaminas e minerais, nutrientes fundamentais para a saúde.

Diante da importância do contato do idoso com esse tipo de trabalho, será preciso ensiná-los as técnicas de cultivo de hortaliças, visando o aumento de áreas produtivas caseiras, utilizarem o cultivo de hortaliças como terapia ocupacional para os idosos, e ajudá-los a comercializar a produção excedente, para que a renda seja revertida para a instituição, seja para as necessidades de manutenção da horta ou para qualquer outra necessidade.

Cabe, portanto, aos profissionais interagir em prol de um atendimento multidisciplinar e completo que proporcione melhorias na qualidade de vida dos idosos (CARVALHO et al., 2007, p.129). Todo trabalho deve ser realizado com dedicação e dinamismo para que os idosos se sintam amparados e estimulados à prática e sejam ajudados em cada atividade.

\subsubsection{Serviço Social}

Apoio social se define como sendo qualquer informação, falada ou não, e/ou auxílio material oferecidos por grupos e/ou pessoas que se conhecem e que resultam em efeitos emocionais e/ou comportamentos positivos. Trata-se de um processo recíproco, ou seja, que gera efeitos positivos. Desse processo se apreende que as pessoas necessitam umas das outras (MINKLER, 1985).

A participação social pode contribuir para a manutenção do sistema de defesa do corpo e diminuir a suscetibilidade à doença. Um envolvimento comunitário, por 
exemplo, pode ser um fator psicossocial significativo na melhoria da confiança pessoal, da satisfação com a vida e da capacidade de enfrentar problemas (VALLA, 1999, p 10).

\section{Exclusão social}

Existem diversos fatores de exclusão social, dentre eles, o acelerado processo de urbanização das cidades, que tem impedido muitos indivíduos idosos de participar da vida em sociedade e impossibilitado a continuidade das relações sociais no meio em que vivem e se movem, comprometendo, assim, sua qualidade de vida. Como a dificuldade financeira das famílias e o consequente aumento na jornada de trabalho, a problemática habitacional traz como consequência a diminuição do envolvimento emocional dentro das famílias e a supressão de momentos de lazer em comum, fazendo com que muitas pessoas idosas prefiram, por elas mesmas, a institucionalização (PRADO e LICHT 2004, citados por ARAUJO et al., 2009, p. 213-218).

\section{QUALIDADE DE VIDA NA TERCEIRA IDADE}

Atualmente, ouve-se com muita frequência a expressão "qualidade de vida" em relação a todas as áreas do conhecimento humano, seja relativa à situação política, social, econômica, familiar, entre tantas, inclusive ao setor saúde, principalmente em se tratando da terceira idade (SOMCHINDA \& FERNANDES, 2003, p.14).

A Organização Mundial da Saúde (OMS) define qualidade de vida (QV) como "a percepção do indivíduo de sua posição na vida no contexto da cultura e sistema de valores nos quais ele vive e em relação aos seus objetivos, expectativas, padrões e preocupações" (SILVA, p.162).

A qualidade de vida, compreendida subjetivamente, é um objeto de prioridade no planejamento, implementação e avaliação das políticas de saúde e decisões de tratamento (OLESON, 1990, citado por SILVA, 2009, p.162). A essência da QV baseiase na experiência de vida de cada pessoa, e só a ela cabe julgá-la, de acordo com as suas preferências e valores (SILVA, 2009, p.162).

Tudo depende da relação que a pessoa estabelece com sua própria velhice (SOARES et al., 2009, p.136).

Existem duas formas básicas de ocorrer mudanças que envolvem essa fase da vida (SOARES et al., 2009, p.136): 
- De maneira consciente e tranquila, reconhecerem o que há de importante nessa etapa de vida para desfrutá-la da melhor maneira, mesmo com limitações, surgindo imagens bem mais positivas da velhice e do envelhecimento.

- Ou com grande intensidade, quando associada à doença e incapacidade, quando os idosos tendem a representar imagens bem negativas da velhice.

Viver bem a velhice depende da interação do idoso com seu contexto de vida, do qual brotam seus valores, sua dimensão social e a história de sua vida (SILVA, 2009, p.163).

\subsection{Aceitação da morte}

A maioria das pessoas não se prepara para a velhice por diversos motivos. Um deles é que essa etapa está associada à ideia da própria morte, tema relativamente evitado pelas pessoas em todas as faixas etárias na atualidade (SOARES et al., 2009, p.136). De acordo com KOVÁCS (2005), a morte faz parte do desenvolvimento humano desde a mais tenra idade e acompanha o ser humano no seu ciclo vital, deixando suas marcas (citado por SOARES et al., 2009, p.136).

A morte é considerada como parte constitutiva da existência humana
(KUBLLER ROSS, 2000, citado por CARVALHO et al., p.551, 2006). É, sem dúvida, uma das poucas coisas de que temos certeza, e sua imprevisibilidade obriga o ser humano a conviver com a sua presença in memorian desde o início ao estágio final do seu desenvolvimento (CARVALHO et al., p.551, 2006).

A negação da velhice e da morte faz com que as pessoas tornem-se resistentes para lidar com e falar sobre elas, numa tentativa consciente ou inconsciente de evitar a dor e o sofrimento. A complexidade, a dificuldade de aceitação e a proibição em se discutir a finitude da vida dificultam a elaboração do medo da morte e do processo de morrer, tanto no âmbito individual quanto no familiar (PY; TREIN, 2006, citados por ARAÚJO et al., 2009, p 213-214).

\section{KASTENBAUM}

AISENBERG (citados por ARAÚJO et al., 2009. p 214-215) apresentam três categorias de medo: medo de morrer, medo da pós-vida e medo da extinção, sendo que cada uma delas se distribui em duas outras modalidades, relacionadas tanto ao medo de sua própria morte quanto ao medo da morte de outros. 
Na categoria do medo de morrer registram-se:

-Sofrimento pessoal e indignidade (morte pessoal);

o sofrimento pessoal associa-se à indesejável expectativa do sofrimento físico, ou seja, à possibilidade de padecer aflição física, o que caracteriza o morrer como um evento aversivo.

a indignidade refere-se à desintegração de si mesmo, tornando-se dependente dos outros e indigno.

-Sofrimento vicário e desintegração vicária (morte dos outros);

o sofrimento vicário relaciona-se ao desconforto de presenciar o sofrimento alheio.

- a demonstração vicária inclui a desagradável previsão do próprio futuro.

$\mathrm{Na}$ categoria do medo da pós-vida apresentam-se as modalidades:

- de medo relacionado ao castigo e à rejeição;

referindo-se, respectivamente, ao medo do que pode acontecer consigo mesmo após a morte, incluindo os medos de ser castigado e de ser rejeitado por Deus. -de retaliação e perda de relacionamento;

- a retaliação está ligada ao medo pela culpa, ou seja, dor de ter feito alguém sofrer em vida, direta ou indiretamente, ou ter sido responsável pela morte de outro.

teme-se, também, a perda de um importante relacionamento pessoal com aquele que vai morrer.

Na categoria de medo da extinção, têmse como modalidade:

- o medo básico da morte;

- está ligado à supressão ou ao deixar de ser, que, ao mesmo tempo, funciona como restaurador e multiplicador de outros medos vinculados.

- os medos vinculados, o abandono e a vulnerabilidade;

o medo da extinção do outro é decorrente da ameaça de abandono e da condição de vulnerabilidade daquele que continua a viver em face da extinção do outro.

\section{KÜBLER-ROSS (citada por} SUSAKI et al., 2006) descreve a identificação dos cinco estágios que um paciente pode vivenciar durante sua terminalidade que são: negação, raiva, barganha, depressão e aceitação. 
-A negação pode ser uma defesa temporária ou, em alguns, casos pode sustentar-se até o fim. $O$ paciente desconfia de troca de exames ou competência da equipe de saúde. Geralmente o pensamento que traduz essa defesa é: "não, eu não, é verdade".

-A raiva é a fase na qual surgem sentimentos de ira, revolta e ressentimento: "porquê eu?". Torna-se mais difícil lidar com o paciente, pois a raiva se propaga em todas as direções, projetando-se no ambiente, muitas vezes, sem "razão plausível".

- Barganha: o doente faz promessas por um prolongamento da vida ou alguns dias sem dor ou males físicos. As barganhas são feitas com Deus, na maioria das vezes e, psicologicamente, podem estar associadas a uma culpa recôndita.

-Depressão pode evidenciar seu alheamento ou estoicismo, com um sentimento de grande perda. As dificuldades do tratamento e hospitalização prolongados aumentam a tristeza que, aliada a outros sentimentos, ocasionam a depressão.

-A aceitação é aquela em que o paciente passa a aceitar a sua situação e seu destino. É o período em que a família pode precisar de ajuda, compreensão e apoio, à medida que o paciente encontra uma certa paz e o círculo de interesse diminui. No entanto, há pacientes que mantêm o conflito com a morte, sem atingir esse estágio.

Não há uma ordem para a ocorrência dessas manifestações, tampouco uma cronologia, sendo que o paciente pode vivenciar mais de uma destas fases, concomitantemente, num mesmo período ou até mesmo não vivenciar algumas delas.

Estas fases são como mecanismos de defesa para enfrentar o processo desconhecido do morrer, em que os conflitos de ordem emocional, material, psicológica, familiar, social, espiritual, entre outros, surgem de forma acentuada, afetando diretamente o relacionamento com a equipe de saúde (KUBLER-ROSS 1968, KOVACS 1992, \& PADUAN 1984, citados por SUSAKI et al., 2006).

Com o envelhecimento, podemos pensar na nossa própria morte. Envelhecer será viver "muito" e é aí que podemos também conceber o risco da perda. A partilha a par do risco, a vida a par do envelhecimento (SANTOS et al., 2009). 
4. CARACTERÍSTICAS GERAIS DOS IDOSOS

Na ILPI do município de Três Corações, residem 52 idosos, sendo 22 homens e 30 mulheres. A idade varia entre 59 e 89 anos.

A maioria dos idosos permanece em seus quartos durante o dia, deitados em suas camas assistindo televisão, ou muitas das vezes sentados em cadeiras na varanda ou na sala de reunião. Outros vão para a sala de televisão para acompanharem as missas e terços. Aqueles mais ativos caminham pelos corredores e pátios à procura de pessoas que lhes dêem atenção. Poucos realizam algum tipo de atividade. Pode-se afirmar que o dia-a-dia dos idosos é marcado pelo "vazio", falta de lazer, entretenimento e outras ocupações. Apesar dessas afirmações, alguns idosos recebem visitas de parentes, outros ou todos recebem visitas de pessoas da cidade. Como pude constatar durante as visitas, alguns idosos se queixam e choram de tristeza e de saudades de parentes, demonstrando carência.

De acordo com informações obtidas, no último dia do mês realizam uma festa com bolo e salgado para comemorarem os aniversários do mês. Aos sábados, acontece a celebração de missa.
Alguns idosos realizam suas refeições em refeitórios, enquanto outros, que não podem andar, realizam em seus leitos acompanhados por funcionários. As refeições possuem horários determinados. Percebe-se que alguns idosos consomem suas refeições sem vontade e prazer.

Deve-se dar atenção para todos os parâmetros, pois os mesmos carecem de atividades interativas capazes de proporcionar estímulo para uma vida mais prazerosa.

\section{CONCLUSÃO}

A partir do estudo realizado, evidencia-se a necessidade de se buscarem estratégias que promovam bem-estar e saúde ao idoso institucionalizado. Os problemas apresentados são desafios que devem ser ultrapassados. Cabe aos diversos profissionais, portanto, tornar real a prática dos conceitos de promoção da saúde dentro desse ambiente, de acordo com as suas possibilidades.

Todos têm direito a uma melhor qualidade de vida, repleta de amor e felicidade, bem como preparados para aceitação da morte digna. 


\section{REFERÊNCIAS}

AMADO, Tânia Campos; ARRUDA, Fell Ilma Kruze Grande de; FERREIRA, Rogério Anderson Rodrigues. Aspectos alimentares, nutricionais e de saúde de idosas atendidas no Núcleo de Atenção ao Idoso - NAI. Recife/ 2005. Arquivo Latino Americano de Nutrição, vol 57, $\mathrm{n}^{\circ} 4$, 2007, $\mathrm{p}$ 366-372. Disponível em: $<$ www.scielo.org.ve/pdf/alan/v57n4/art 09.pdf $>$. Acesso em: 18 de fevereiro de 2010.

ANDRADE, Ana Carla Alves de; LIMA, Fernanda Raquel Alves de; SILVA, Luciana Fernandes Albuquerque; SANTOS, Silvana Sidney Costa. Depressão em idosos de uma instituição de longa permanência (ILP): Proposta de ação de enfermagem. 2005, p 57-66.

Disponível em:

$<$ www.seer.ufrgs.br/index.../RevistaGau chadeEnfermagem $>$. Acesso em: $20 \mathrm{de}$ fevereiro de 2010.

ARAÚJO, Luciene Pires de; HELMER, Denise Santoro; GOMES, Lucy; FUKUDA, Cláudia Cristina; FREITAS, Marta Helena de. Medo à morte e ao morrer em idosas institucionalizadas e não institucionalizadas. 2009, p 213 218. Disponível em:

<periodicos.uem.br/ojs/index.php/.../arti cle/.../6936>. Acesso em: 12 de abril de 2010 .

ARAÚJO, Ludgleydson Fernandes de; CARVALHO, Virgínia Ângela M. de Lucena. Aspectos Sócio-Históricos e Psicológicos da Velhice. Revista de Humanidades, vol.6, n.13, dez.2004/jan.2005. Disponível em $<$ http://www.seol.com.br/mneme $>$. Acesso: 28 de abril de 2010.
BANDEIRA, Eliana Márcia Fialho de Sousa; PIMENTA, Fausto Aloísio Pedrosa; SOUZA, Miraneide Carmo de. Atenção à saúde do idoso. 2006, p186. Disponível em:

$<$ http://www.prolongevidade.org.br/Upl oad/Downloads/5 Util.pdf $>$. Acesso em fevereiro de 2010.

BENEDETTI, Tânia R Bertoldo; BORGES, Lucélia Justino; PETROSKI, Edio Luiz; GONÇALVES, Lúcia Hisako Takase. Atividade física e estado de saúde mental de idosos. 2008. Disponível em:

$<$ www.scielo.br/scielo.php? script...89102008000200016 $>$. Acesso em: 22 de março de 2010.

CAMPOS, Maria Teresa Fialho de Sousa; MONTEIRO, Josefina Bressan Resende; Ana ORNELAS, Paula Rodrigues de Castro. Fatores que afetam o consumo alimentar e a nutrição do idoso. 2000, p 157-165. Disponível em: $<$ www.portaldoenvelhecimento.net/artig os/z435.pdf > . Acesso em: 02 de março de 2010 .

CARVALHO, Lucimeire Santos; OLIVEIRA, Milena Arão da Silva; PORTELA, Sandra Cabral; SILVA, Cátia Andrade da; OLIVEIRA, Ana Carla Petersen de; CAMARGO, Climene Laura de. A morte e o morrer no cotidiano de estudantes de enfermagem. 2006, p 551-557. Disponível em:

$<$ http://www.facenf.uerj.br/v14n4/v14n 4a10.pdf $>$. Acesso em: 18 de março de 2010.

CARDOSO, Renata Magalhães.

Isolamento existencial, um caminho sem volta. Revista Virtual de Psicologia Hospitalar e da Saúde. Belo Horizonte, Jan-Jun, Ano 2, n.3, 2006. Disponível em: $<$ susanaalamy.sites.uol.com.br/psic 
opio_n3_23.pdf $>$. Acesso em 02 de março de 2010.

CARVALHO, Maitê Peres de; OLIVEIRA, Verônica de; CHAVES, Sílvia Tavares; FERNANDES, Tiane da Fontoura; FERREIRA, Ana Lia Dutra; FONSECA, Priscila Guterres da; ÁLVARES, Liege Mata; SILVA, Flaviano Moreira da. Intervenção Fisioterápica na Terceira Idade: Uma visão reabilitadora. Revista de Saúde da UCPEL, Pelotas, v.1,n.2, Jul./Dez. 2007. Disponível em:

$<$ www.ucpel.tche.br/revistadesaude/edic oes/2007-2/125-142.pdf $>$. Acesso em: 13 de março de 2010.

GUIDETTI, Andréia Arruda; PEREIRA, Aline dos Santos. A importância da comunicação na socialização. 2008, p 119-136.

Disponível em:

$<$ sare.unianhanguera.edu.br/index.php/r educ/.../168>. Acesso em : 02 de abril de 2010 .

\section{HERÉDIA, Vania Beatriz Merlotti.}

Livro: Idoso asilado: um estudo gerontológico. 2004, 133 p. Disponível em: <books.google.com.br>. Acesso em: 05 de abril de 2010.

JÚNIOR, Renato ampos Freire; TAVARES, Maria de Fátima Lobato. A saúde sob o olhar do idoso institucionalizado: conhecendo e valorizando sua opinião. 2005, vol. 9, n. 16, p 147-158. Disponível em: $<$ http://www.scielo.br/scielo.php $>$.

Acesso em: 20 de abril de 2010. LENARDT, Maria Helena; MICHEL, Tatiane; TALLMANN, Ana Elisa Casara. A condição de saúde de idosas residentes em instituição de longa Permanência. 2009, p 227-236.

Disponível em:

$<$ http://ojs.c3sl.ufpr.br/ojs2/index.php/c ogitare/article/viewFile/15608/1038>. Acesso em: 23 de abril de 2010.
LENARDT, Maria Helena; WILLIG, Mariluci Hautsch; SILVA, Scheilla Cristina da.AdrianoYoshio Shimbo; TALLMANN, Ana Elisa Casara; MARUO, Gláucia Harume. O idoso institucionalizado e a cultura de cuidados profissionais. 2006, p 117123. Disponível em:

$<$ http://ojs.c3sl.ufpr.br/ojs2/index.php/c ogitare/article/viewFile/6853/4867>.

Acesso em 14 de abril de 2010.

MARCONCIN, Priscila; REAL, Nuno Corte; DIAS, Cláudia; FONSECA, António Manuel. A representação das Universidades Seniores, o bem-estar subjetivo e a prática da atividade física em idosos. REVISTA TRANSDISCIPLINAR DE GERONTOLOGIA. Universidade Sénior Contemporânea, Ano IV volume III. Número 2, p 1-104, 2010. Disponível em: $<$ http://usc.no.sapo.pt/RTG_III 2.pdf $>$. Acesso em 12 de março de 2010.

MELO, Gislane Ferreira de; MENDONÇA, Aguinis de Cássia; GIAVONI, Adriana; MADUREIRA, Alberto Saturno. Análise do nível de atividade física nas casas de repouso e instituições filantrópicas (asilos) do Distrito Federal. Revista Digital Buenos Aires - Año 9 - $\mathbf{N}^{\circ} 62$ - Julio de 2003. Disponível em: $<$ http://www.efdeportes.com/efd62/a silos.htm>.Acesso em 12 de março de 2010 .

MONTOVANI, Efigênia Passarelli; O processo de envelhecimento e sua relação com a nutrição e a atividade física. p 165-172. Disponível em: $<$ www.fef.unicamp.br/...ql.../diagnostic o_vinhedo_cap13.pdf $>$. Acesso em 14 de abril de 2010 .

MOTTA, Luciana Branco da; CALDAS, Célia Pereira; ASSIS, Mônica de. A formação de 
profissionais para a atenção integral à saúde do idoso: a experiência interdisciplinar do NAI UNATI/UERJ. Ciência e Saúde Coletiva, 2008, vol. 13, n. 4, p. 11431151. Disponível em:

$<$ www.scielo.br/scielo.php? pid $=\mathrm{S} 1413 \ldots$...script $=$ sci $>$. Acesso em 01 de março de 2010.

OLIVEIRA, Paula Fernanda de; Perfil Alimentar e Nutricional de idosos autônomos hospitalizados pelo Sistema Único de Saúde (SUS) e por (Convênio) no Município de

Araraquara - SP. 2008, 103 p.

Disponível em:

$<$ dominiopublico.qprocura.com.br/.../69

Teses-e-Dissertaes.html,13279>.

Acesso em: 10 de março de 2010.

PAVAN, Fábio José; MENEGHEL, Stela Nazareth; JUNGES, José Roque. Mulheres idosas enfrentando a institucionalização. Caderno de Saúde Pública vol.24 no.9 Rio de Janeiro Setembro de 2008. Disponível em:

$<$ http://www.scielosp.org/scielo.php $>$. Acesso em 18 de fevereiro de 2010.

SANTOS, Ana Filipa R; LIMA, Luísa Nobre; SANTOS, Paula Isabel.

Voluntariado e ansiedade perante a morte no idoso aposentado. Revista da Faculdade de Ciências Humanas e Sociais. 2009, p. 74-84. Disponível em: $<$ https://bdigital.ufp.pt/dspace/bitstream /10284/.../74-84_\%20FCHS06-11.pdf $>$. Acesso em 29 de abril de 2010.

SILVA, José Vítor orgs. Saúde do Idoso e a Enfermagem de envelhecimento sob múltiplos aspectos. São Paulo: Iátria, $1^{\mathrm{a}}$ edição. 2009, p.320. Capítulo $10^{\circ}$ Nutrição do Idoso. SOUZA, Junqueira, p.128-170. Capítulo $14^{\circ}$ Depresão no Idoso. GALHARDO, Vítor Ângelo Carlucio, p.183-209.
SOARES, Juliana Augusto; SILVA, Rilza Freitas; ROSA, Larissa Jardim; GALVÃO, Érica Aparecida; RIBEIRO, Raquel Noel. O idoso institucionalizado e a reflexão sobre a própria morte. Revista Kairós, São Paulo, jan. 2009, p. 135-147. Disponível em:

$<$ http://revistas.pucsp.br/index.php/kair os/article/viewFile/2784/1872>. Acesso em: 20 de maio de 2010.

SOMCHINDA, Aksara; FERNANDES, Fernando Chamoschine. Saúde e qualidade de vida na terceira idade: uma introspeç̧ão dos idosos institucionalizados. 2003, p 1-87. Disponível em:

$<\underline{\text { http://egroups.unb.br/fs/sbc/sbc2003ab }}$ o/saude e qualidade de vida na tercei ra idade.pdf $>$. Acesso em: 25 de março de 2010.

SUSAKI, Tatiana Thaller; SILVA, Maria Júlia Paes da; POSSARI, João Francisco. Identificação das fases do processo de morrer pelos profissionais de Enfermagem. Acta paul. enferm. vol.19, nº2-São Paulo Apr./June 2006. Disponível em: $<$ http://www.scielo.br/scielo.php? pid $=$ S010321002006000200004\&script $=$ sci arttext $>$. Acesso em $23 \mathrm{de}$ fevereiro de 2010.

VALLA, Victor Vicente. Educação popular, saúde comunitária e apoio social numa conjuntura de globalização. 1999, p 7-14. Disponível em:

$<$ http://www.scielosp.org/pdf/csp/v15s2 /1283.pdf $>$. Acesso em 12 de fevereiro de 2010.

VIVAN, Analise de Souza; ARGIMON, Irani Iracema de Lima. Estratégias de enfrentamento, dificuldades funcionais e fatores associados em idosos institucionalizados. 2009. Disponível em: $<$ http://www.scielosp.org/pdf/csp/v25n2 
122.pdf $>$. Acesso em 25 de abril de 2010 . 
ANEXO

\section{Poema}

\section{A voz do Ancião}

Se o meu andar é hesitante

e as minhas mãos trêmulas, ampara-me.

Se a minha audição não é boa, e tenho de me

esforçar para ouvir o que me dizes, procura entender-me.

Se a minha visão é imperfeita e o meu entendimento escasso,

$$
\text { ajuda-me com paciência. }
$$

Se minha mão treme e derrubo comida na mesa ou no chão, por favor, não te irrites, tentei fazer o que pude.

Se me encontrares na rua, não faças de conta que não me viste.

Pára para conversar comigo. Sinto-me só.

Se, na tua sensibilidade, me vires triste e só, simplesmente partilha comigo um sorriso e sê solidário.

Se te contei pela terceira vez a mesma história num só dia, não me repreendas, simplesmente ouve-me.

Se me comporto como uma criança, cerca-me de carinho.

Se estou doente e sou um peso, não me abandones.

Se estou com medo da morte e tento negá-la, por favor, ajuda-me na preparação para o adeus.

(Autor desconhecido) 